\title{
Effect of Annealing Temperature on Soft Magnetic Properties of Cold Rolled 0.30 mm Thick Fe-6.5wt.\%Si Foils
}

\author{
X. S. Fang, J. P. Lin, Y. F. Liang, F. Ye*, L. Q. Zhang, and G. L. Chen \\ State Key Laboratory for Advanced Metals and Materials, University of Science and Technology Beijing, Beijing 100083, PR China
}

(Received 25 April 2011, Received in final form 28 May 2011, Accepted 29 May 2011)

\begin{abstract}
$0.30 \mathrm{~mm}$ thick and $90 \mathrm{~mm}$ wide thin foils made of $\mathrm{Fe}-6.5 \mathrm{wt} . \% \mathrm{Si}$ alloy were successfully fabricated by traditional rolling. The as-rolled sheets had good shapes and shining metal luster. The effects of annealing temperature on the magnetic properties of the sheets were investigated. Excellent Dc properties $\left(\mathrm{H}_{\mathrm{c}}: 11.55 \mathrm{~A} / \mathrm{m}, \mu_{\mathrm{m}}\right.$ : 23710, and $B_{s}: 1.439 \mathrm{~T}$ ) were obtained at an annealing temperature of $1453 \mathrm{~K}$ for $1.5 \mathrm{~h}$. At low frequencies $(\leq 1 \mathrm{kHz})$, heat treatment temperature has little effect on iron loss which remained at the level of $9.8 \mathrm{~W} / \mathrm{kg}$. Annealing at $1273 \mathrm{~K}$ for $1.5 \mathrm{~h}$ is optimum for frequencies above $5 \mathrm{kHz}$.
\end{abstract}

Keywords: Fe-6.5wt.\% Si alloy, rolling, soft magnetic properties

\section{Introduction}

Fe-6.5wt.\%Si alloy (all compositions in this paper are in wt.\% unless otherwise noted) has good perspective applications, such as in transformer cores, magnetic devices at high frequencies, and other electrical devices due to its high relative permeability, low coercive force, high electrical resistivity, and near zero magnetostriction [1,2].

However, the workability of those alloys falls sharply as the silicon content increases, and it is difficult to produce the Fe- $6.5 \% \mathrm{Si}$ alloy thin foil by using traditional processes, such as cold rolling, which dramatically restricts the application of this alloy [3]. Several fabrication methods have been developed to avoid the brittleness of this Fe-6.5\% Si alloy, such as rapid quenching [4], chemical vapor deposition [5], hot dipping process followed by diffusion annealing [6], magnetron sputtering [7], etc.

Our previous studies suggested that boron microalloying could be used to improve of the ductility of the Fe$6.5 \% \mathrm{Si}$ alloy and thin sheets $(0.28-0.30 \mathrm{~mm}$ in thickness) were successfully fabricated by warm rolling after hot rolling. Further, the sheets can be cold rolled to 0.03-0.05 $\mathrm{mm}$ without intermediate annealing [8-10].

The soft magnetic properties of the $\mathrm{Fe}-6.5 \% \mathrm{Si}$ alloy vary significantly with heat treatment. Roy et al. [11] reported that the soft magnetic properties of melt spinning

*Corresponding author: Tel: +86-10-62333899

Fax: +86-10-62333447, e-mail: yefeng@skl.ustb.edu.cn wide ribbons of $\mathrm{Fe}-6.5 \% \mathrm{Si}$ alloy were enhanced with a reduction in coercivity from $150 \mathrm{~A} / \mathrm{m}$ in the as-cast state to $45 \mathrm{~A} / \mathrm{m}$ in the annealed condition at $1123 \mathrm{~K}$. It was also reported that the spray-formed and rolled binary Fe$6.5 \% \mathrm{Si}$ alloy exhibited the best magnetic properties with a $\mu_{\mathrm{m}}$ of 14000 and $\mathrm{H}_{\mathrm{c}}$ of $45 \mathrm{~A} / \mathrm{m}$ after heat treatment for $1 \mathrm{~h}$ at $1523 \mathrm{~K}$, and these values were ascribed to the recrystallization and coarse grain size $(\sim 0.5 \mathrm{~mm})$ [12]. Recently, we have studied the effect annealing temperature on magnetic properties of cold rolled $\mathrm{Fe}-6.5 \% \mathrm{Si}$ alloy with a thickness of $0.05 \mathrm{~mm}$. The results showed that a higher annealing temperature was beneficial for Dc properties, while the Ac properties for the high frequency $(>10 \mathrm{kHz})$ reached a maximum at $1373 \mathrm{~K} \mathrm{[10].}$

$0.30 \mathrm{~mm}$ thick silicon steel sheets are commonly adopted for electrical motors. Annealing is a key process to guarantee the magnetic properties of the core. In this work, we successfully fabricated $1 \mathrm{~m}$ long, $90 \mathrm{~mm}$ wide, and $0.30 \mathrm{~mm}$ thin ribbons of cold rolled $\mathrm{Fe}-6.5 \% \mathrm{Si}$ alloy, and measured the magnetic properties (maximum relative permeability, coercive force, saturation magnetic induction, and core loss) at different annealing temperatures. These are important for designing a motor with high silicon steel cores.

\section{Experimental}

The starting material, with compositions (in wt $\%$ ) of 6.50 Si, $0.050 \mathrm{~B}, 0.031 \mathrm{Mn}, 0.012 \mathrm{P}, 0.0047 \mathrm{~S}, 0.022 \mathrm{C}$, 
and balance Fe, was melted in an induction vacuum furnace. The as-cast ingot was then homogenized and forged into a $30 \mathrm{~mm}$ thick plate. The rolling process schedule of the high silicon steel has been shown elsewhere [8]. After proper heat treatment, the warm-rolled sheets (about 1.5 $\mathrm{mm}$ in thickness) can be cold rolled to $0.30 \mathrm{~mm}$ without further annealing.

To measure the soft magnetic properties, ring-like samples prepared according to the JJG493-87 standard were machined from $0.30 \mathrm{~mm}$-thick cold rolled $\mathrm{Fe}-6.5 \% \mathrm{Si}$ alloy sheets, as shown in Fig. 1. The samples were heat treated at different temperatures in a vacuum and $\mathrm{MgO}$ powder was used to prevent conglutination of the belt. Dc properties, such as $\mathrm{H}_{\mathrm{c}}$ : coercive force, $\mathrm{B}_{\mathrm{s}}$ : saturation magnetic induction, $\mu_{\mathrm{m}}$ : maximum relative permeability, and Ac properties, and especially core loss, were obtained.

\section{Results and Discussion}

Fig. 2 shows the appearance of the cold rolled Fe$6.5 \% \mathrm{Si}$ sheets with thicknesses of $0.30 \mathrm{~mm}$ and widths of

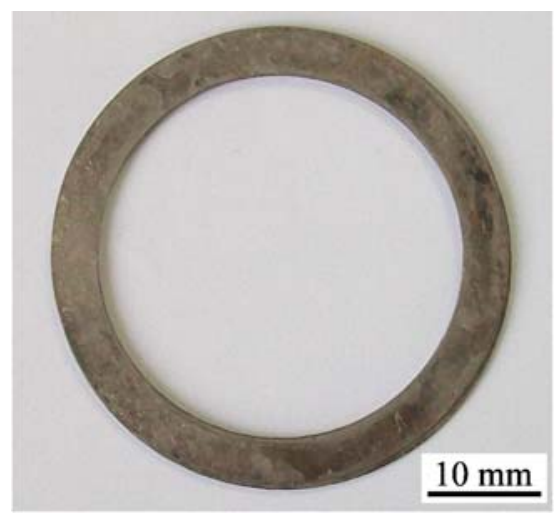

Fig. 1. Ring shape core for magnetic measurements for the cold rolled $\mathrm{Fe}-6.5 \% \mathrm{Si}$ alloy sheets.

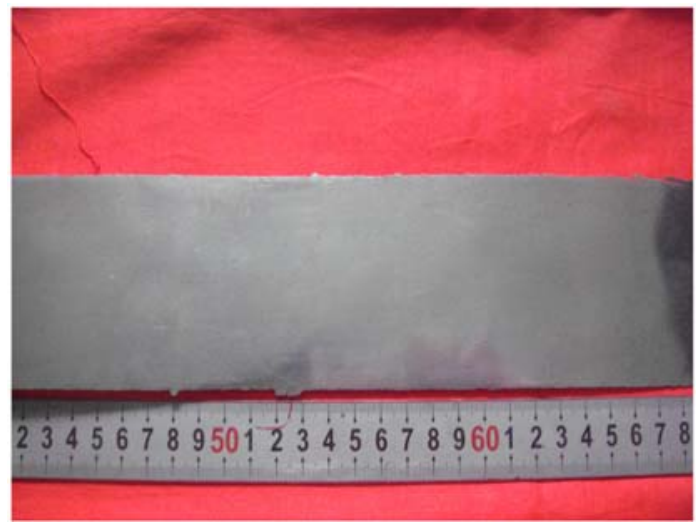

Fig. 2. The cold rolled Fe-6.5\% Si alloy sheet with a thickness of $0.30 \mathrm{~mm}$ and width of $90 \mathrm{~mm}$.
$90 \mathrm{~mm}$. It could be observed that the surfaces of the sheets are smooth and there is little fluctuation in thickness along the rolling direction. The cold rolling direction is along the hot rolling direction which guarantees the continuity of the sheet. We did not observe any ductility decrease with time during this process, as reported by Ros-Yanez et al. [13].

The cold rolled sheets prepared for magnetic measurements were annealed at temperatures of 1173, 1273, 1373, and $1453 \mathrm{~K}$ in vacuum for $1.5 \mathrm{~h}$. The optical microstructure of annealed Fe-6.5\% Si alloy sheets is shown in Fig. 3 . It can be observed that at the low annealing temperature of $1173 \mathrm{~K}$, only primary recrystallization occurred and the grain size was small. When the temperature increased from 1273 to $1453 \mathrm{~K}$, some abnormal huge grains appeared and secondary recrystallization is almost complete at the temperature of $1453 \mathrm{~K}$. The averaged grain size changed from 150 to $900 \mu \mathrm{m}$.

The Dc magnetic properties were measured at a maximum applied field of $4000 \mathrm{~A} / \mathrm{m}$. Fig. 4 presents the variation of $H_{c}, B_{s}$, and $\mu_{m}$. The coercive force decreases linearly with the annealing temperature and achieves a lowest value of $11.55 \mathrm{~A} / \mathrm{m}$ after annealing at $1453 \mathrm{~K}$. On the other hand, the maximum permeability continuously increases with annealing temperature and reaches a maximum when the sheets were heat treated at $1453 \mathrm{~K}$, although a little fluctuation at $1373 \mathrm{~K}$ was observed. The saturation magnetic induction reaches a maximum at an annealing temperature of $1273 \mathrm{~K}$ and then decreases gradually with annealing temperature. It gets saturated after $1373 \mathrm{~K}$. The annealing temperature dependence of Dc properties is attributable to the grain size effect. A typical Dc result for $1453 \mathrm{~K}$ and $1.5 \mathrm{~h}$ are $\mathrm{H}_{\mathrm{c}}: 11.55 \mathrm{~A} / \mathrm{m}, \mu_{\mathrm{m}}: 23710$, and $\mathrm{B}_{\mathrm{s}}$ :
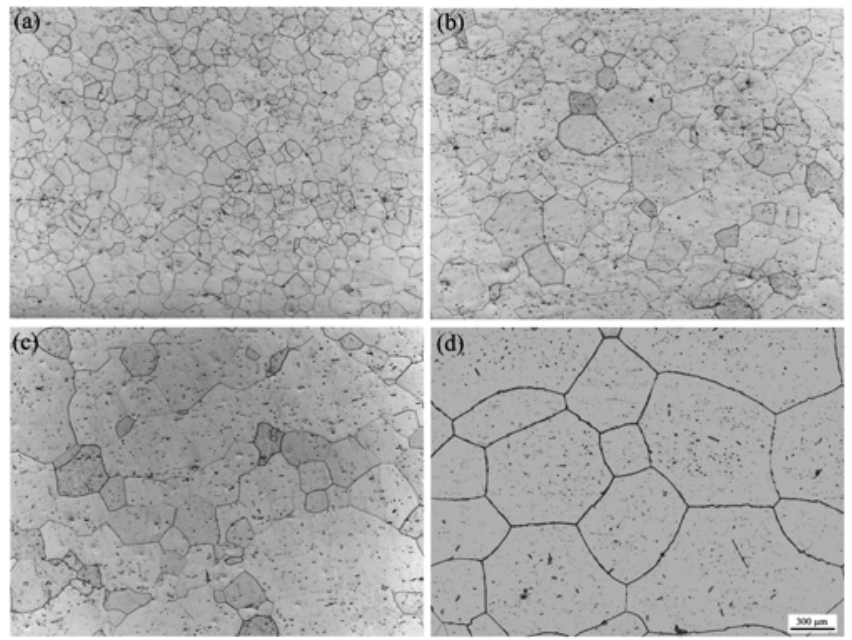

Fig. 3. The optical microstructure of Fe- $6.5 \% \mathrm{Si}$ alloy sheets annealed at different annealing temperatures: (a) $1173 \mathrm{~K}$, (b) $1273 \mathrm{~K}$, (c) $1373 \mathrm{~K}$, (d) $1453 \mathrm{~K}$. 


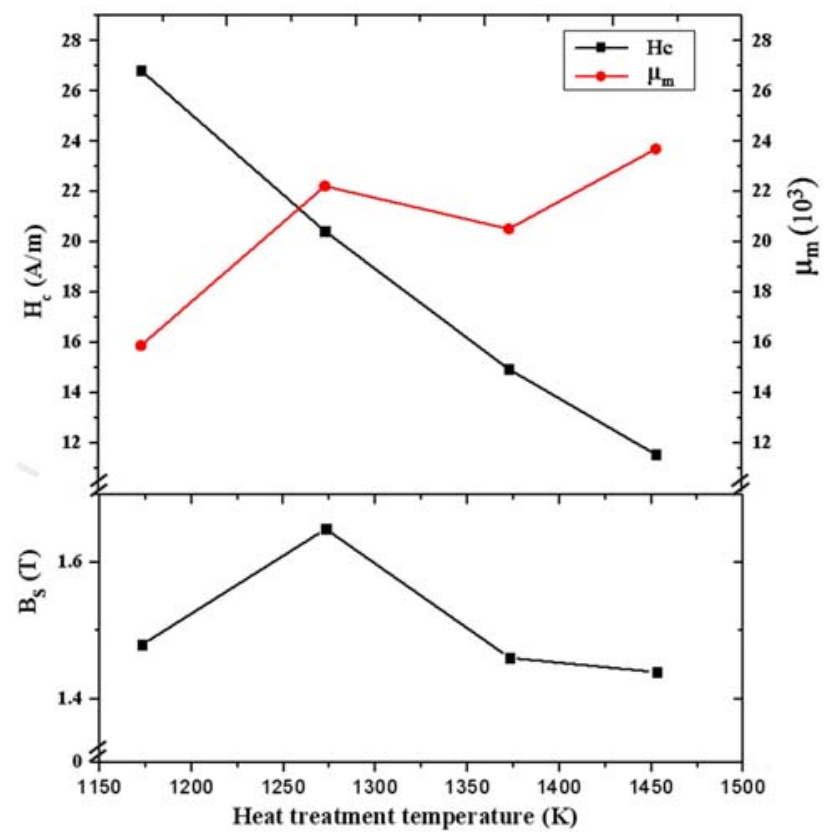

Fig. 4. Variation of the Dc magnetic properties $\left(\mathrm{H}_{\mathrm{c}}\right.$ : coercive force, $\mathrm{B}_{\mathrm{s}}$ : saturation magnetic induction, $\mu_{\mathrm{m}}$ : maximum relative permeability) of a $0.30 \mathrm{~mm}$ thick cold rolled $\mathrm{Fe}-6.5 \% \mathrm{Si}$ sheet with the heat treatment temperature.

$1.439 \mathrm{~T}$, which shows better properties compared with the CVD formed $0.30 \mathrm{~mm}$ thick alloy sheet with $\mu_{\mathrm{m}}: 25000$ and $\mathrm{B}_{\mathrm{s}}: 1.30 \mathrm{~T}[15]$.

The core losses of the cold rolled Fe-6.5\% Si sheets were measured at different inductions and frequencies. Magnetic induction ranged from 1 to $0.07 \mathrm{~T}$, and the frequency ranged from 0.4 to $40 \mathrm{kHz}$.

As shown in Fig. 5, the core losses are insensitive to the annealing temperature for the frequencies below $1 \mathrm{kHz}$, which maintains at the level of $9.8 \mathrm{~W} / \mathrm{kg}$. However, when the frequencies are above $1 \mathrm{kHz}$, the sample treated at $1273 \mathrm{~K}$ had less core loss than those treated at other temperatures. For the whole range of tested frequencies, the samples treated at 1373 and $1453 \mathrm{~K}$ had the same core losses. This can be attributed to the variation of grain sizes. Kim et al. [14] reported that the grain size had a different effect on the eddy current loss and hysteresis loss, which are the primary components in the total iron loss. So it has an optimum grain size for different frequencies to obtain a minimum iron loss. A higher annealing temperature leads to a larger grain size and makes hysteresis loss decrease and eddy current loss increase. In our experiment, the effect of grain size on the iron loss is not significant at low frequencies $(<1 \mathrm{kHz})$. However, when the frequencies are higher than $5 \mathrm{kHz}$, the increase of the eddy current loss is more significant for larger grained samples and the decrease of hysteresis loss is

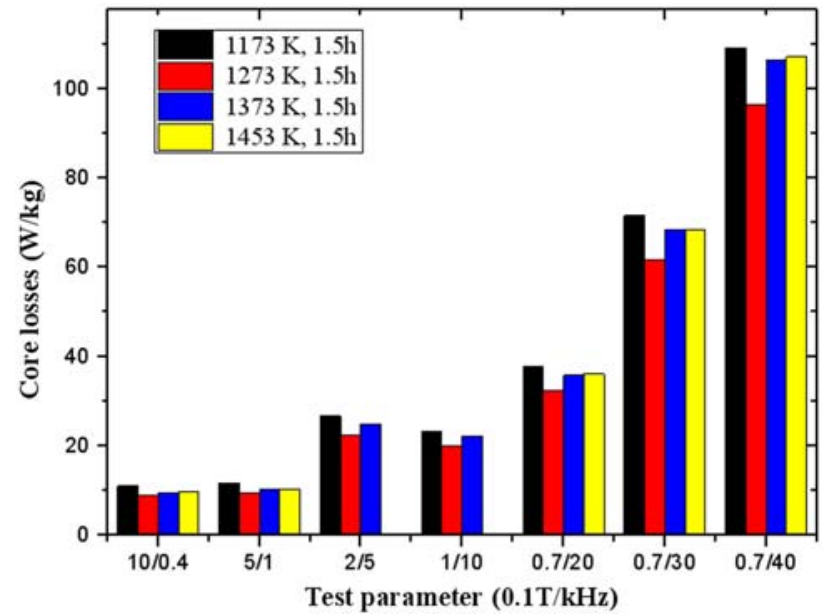

Fig. 5. Core losses from $400 \mathrm{~Hz}$ to $40 \mathrm{kHz}$ of the $0.30 \mathrm{~mm}$ thick cold rolled $\mathrm{Fe}-6.5 \% \mathrm{Si}$ sheet with different heat treatment temperatures.

secondary. Hence the optimum grain size decreases as the frequency increases. Therefore the annealing temperature for a $0.30 \mathrm{~mm}$ thick cold rolled $\mathrm{Fe}-6.5 \% \mathrm{Si}$ sheet should be lower than $1273 \mathrm{~K}$ to avoid a large grain size for frequencies above $5 \mathrm{kHz}$. The result is different from those of the $0.05 \mathrm{~mm}$ thick cold rolled sheet [10]. This is thought to be due to the fact that the eddy current losses decrease with the thickness, but increase rapidly in approximate proportion to the square of the frequency [15].

\section{Conclusions}

The cold rolling of the Fe- $6.5 \% \mathrm{Si}$ sheets with thicknesses of $0.30 \mathrm{~mm}$ and widths of $90 \mathrm{~mm}$ could be conducted after the proper thermo-mechanical process of forging, hot rolling, warm rolling, and heat treatment. Cold rolling technique offers a great perspective application of Fe- $6.5 \% \mathrm{Si}$ foils for electrical motors. The effects of annealing temperature on magnetic properties of the sheets were as follows:

(1) The coercivity reaches a minimum value (about $11.55 \mathrm{~A} / \mathrm{m}$ ) and the permeability becomes maximum (about 23710) at the annealing temperature of $1453 \mathrm{~K}$.

(2) At low frequencies $(1 \mathrm{kHz})$, the heat treatment temperature has little effect on the iron loss which remains at the level of $9.8 \mathrm{~W} / \mathrm{kg}$. Annealing at $1273 \mathrm{~K}$ for $1.5 \mathrm{~h}$ is optimum for frequencies above $5 \mathrm{kHz}$.

\section{Acknowledgements}

Financial support from the National High-tech Research and Development Program of China (No. 2009AA033201), the Major State Basic Research Development Program of 
China (973 Program, No. 2011CB606304), and Program for New Century Excellent Talents in China University (NCET-09-0220) is gratefully acknowledged.

\section{References}

[1] R. M. Bozorth, Ferromagnetism, D. Van Nostrand Company, New York (1951) pp. 67-101.

[2] K. I. Arai and K. J. Ishiyama, J. Magn. Magn. Mater. 133, 233 (1994).

[3] M. Komatsubara, K. Sadahiro, O. Kondo, T. Takamiya, and A. Honda, J. Magn. Magn. Mater. 242-245, 212 (2002).

[4] T. Watanabe, H. Fujii, H. Oikawa, and K. I. Arai, Acta Metal. 37, 941 (1989).

[5] M. Abe, Y. Takada, T. Murakami, and Y. Mihara, J. Mater. Eng. 11, 109 (1989).

[6] T. R. Yanez, Y. Houbaert, and V. G. Rodriguez, J. Appl. Phys. 91, 7857 (2002).
[7] G. K. Tian and X. F. Bi, J. Alloy. Compd. 502, 1 (2010).

[8] K. N. Kim, L. M. Pan, J. P. Lin, Y. L. Wang, Z. Lin, and G. L. Chen, J. Magn. Magn. Mater. 277, 331 (2004).

[9] G. L. Chen, J. H. Peng, and W. X. Xu, Intermetallics 6, 315 (1998).

[10] Y. F. Liang, F. Ye, J. P. Lin, Y. L. Wang, and G. L. Chen, J. Alloys. Compd. 491, 268 (2010).

[11] R. K. Roy, A. K. Panda, M. Ghosh, A. Mitra, and R. N. Ghosh, J. Magn. Magn. Mater. 321, 2865 (2009).

[12] C. Bolfarini, M. C. Alves-Silva, A. M. Jorge-Jr, C. S. Kiminami, and W. J. Botta, J. Magn. Magn. Mater. 320, e653 (2008).

[13] T. Ros-Yanez, Y. Houbaert, O. Fischer, and J. Schneider, J. Mater. Process. Technol. 143-144, 916 (2003).

[14] Y. H. Kim, M. Ohkawa, and K. I. Arai, IEEE Trans. Magn. 29, 3535 (1993).

[15] H. Haiji, K. Okada, T. Hiratani, M. Abe, and M. Ninomiya, J. Magn. Magn. Mater. 160, 109 (1996). 